\title{
Laparoscopic ventral hernia repair is safe and cost effective
}

\author{
G. Beldi, R. Ipaktchi, M. Wagner, B. Gloor, D. Candinas \\ Department of Visceral and Transplant Surgery, Inselspital University Bern, CH-3010 Bern, Switzerland
}

Received: 20 June 2005/Accepted: 8 September 2005/Online publication: 7 December 2005

\begin{abstract}
Background: Ventral hernia repair is increasingly performed by laparoscopic means since the introduction of dual-layer meshes. This study aimed to compare the early complications and cost effectiveness of open hernia repair with those associated with laparoscopic repair. Methods: Open ventral hernia repair was performed for 92 consecutive patients using a Vypro mesh, followed by laparoscopic repair for 49 consecutive patients using a Parietene composite mesh.

Results: The rate of surgical-site infections was significantly higher with open ventral hernia repair (13 vs 1 ; $p=0.03$ ). The median length of hospital stay was significantly shorter with laparoscopic surgery (7 vs 6 days; $p=0.02)$. For laparoscopic repair, the direct operative costs were higher (2,314 vs 2,853 euros; $p=0.03)$, and the overall hospital costs were lower $(9,787$ vs 7,654 euros; $p=0.02$ ).

Conclusions: Laparoscopic ventral hernia repair leads to fewer surgical-site infections and a shorter hospital stay than open repair. Despite increased operative costs, overall hospital costs are lowered by laparoscopic ventral hernia repair.
\end{abstract}

Key words: Cost - Laparoscopy - Mesh - Polypropylene - Ventral hernia

The use of mesh for ventral hernia repair has been proved superior to direct suturing methods in terms of long-term recurrence [11]. With the introduction of new mesh types, ventral hernia repair via laparoscopic means is gaining increasing acceptance. In the initial series, expanded polytetrafluoroethylene (ePTFE) meshes were used predominantly [7]. However, because of the small

Presented at 13th European Association for Endoscopic Surgery (EAES) Congress, Venice, Italy, 1-4 June 2005

Correspondence to: $\mathrm{B}$. Gloor pore size, these meshes are, without impregnation of disinfectants, more prone to infection $[4,6]$.

Polyester and polypropylene meshes were introduced in ventral hernia repair with the development of duallayer technology. These meshes have a larger pore size and different biologic properties than ePTFE [12]. A marked inflammatory reaction leads to incorporation of the mesh into the abdominal wall. Synthesis of a neoperitoneal layer combined with integration of the mesh minimizes the risk for infection [12].

No study comparing open and laparoscopic ventral hernia repair using polypropylene-based meshes had been performed. Therefore, we conducted a cohort study comparing these two methods in terms of postoperative morbidity and treatment costs in a single center.

\section{Materials and methods}

All patients with mesh implantation for ventral hernia repair who underwent surgery between March 2003 and March 2005 were included in the study. The indication for mesh implantation was a minimum hernia diameter of $2 \mathrm{~cm}$. Five patients were excluded from laparoscopic surgery: four who had general contraindications for laparoscopy and one who was not willing to undergo laparoscopic hernia repair.

Patient data for open repair were reviewed retrospectively from the medical records. The data for patients who had undergone laparoscopic repair were collected prospectively. The collected data included the patients' age, gender, body mass index (BMI), surgical history, risk factors, comorbidity, mesh size, complications, and follow-up evaluation.

\section{Open repair technique}

For open repair, patients were in the supine position with arms abducted. Single-shot antibiotic prophylactics with amoxicillin/clavulanic acid $1.2 \mathrm{~g}$ (Augmentin; GlaxoSmithKline, Münchenbuchsee, Switzerland) was administered intravenously. The sac of the hernia was excised in most cases. A Vypro mesh (Ethicon Schweiz, Johnson \& Johnson Medical, CH-8957 Spreitenbach, Switzerland) was used. The fascia was adapted with a running PDS 1 suture. The mesh size was chosen so as to overlap the rectus sheath at least $5 \mathrm{~cm}$. The mesh was placed on the dorsal rectus sheath and fixed with polypropylene sutures. Closed suction drains were placed onto the mesh and also subcutaneously. The patient was not allowed to lift weights for 4 weeks postoperatively. 


\section{Laparoscopic repair technique}

For laparoscopic repair, the patients were in the supine position with arms abducted. Single-shot antibiotic prophylactics with amoxicillin/ clavulanic acid were administered. A pneumoperitoneum of $12 \mathrm{mmHg}$ was established using a limited open technique. A minimum of two additional trocars were inserted in the left flank, and complete adhesiolysis of the abdominal wall was performed.

A Parietene composite mesh (Sofradim, Trévoux, France) was used for all patients. The mesh selected was larger than the hernia defect, allowing at least $4 \mathrm{~cm}$ of mesh beyond the perimeter of the fascial defect. The mesh was prepared by placing two types of sutures alternatively (Prolene 0 and Ethilon 0 ) on the edge of the mesh every 3 to $4 \mathrm{~cm}$. The mesh was rolled and inserted into the abdominal cavity. The sutures were lifted above the abdominal wall with a suture passer. After reduction of the intraabdominal pressure to $8 \mathrm{mmHg}$, the threads were knotted extracorporeally. The patient was not allowed to lift weights for 4 weeks postoperatively.

\section{Cost analysis}

Operative costs were calculated by assessing all resources, adding an average cost factor for operative time. In-hospital costs were provided by the administration of the hospital integrating personnel salaries, materials, and equipment. The results are presented in euros using values for the year 2005 .

\section{Statistical analysis}

Results are expressed as median and range for age, BMI, operative time, mesh size, and length of stay. Costs are expressed as mean \pm standard deviation. The MannWhitney $U$ test was used to compare age, BMI, operative time, mesh size, and length of stay. The Student's $t$-test was used to compare costs. Fisher's exact test was performed to compare proportions. All $p$ values less than 0.05 were considered statistically significant. Data were analyzed statistically with SPSS Software (SPSS Inc., Chicago, IL, USA).

\section{Results}

Open hernia repair was performed for 92 consecutive patients: 87 between March 2003 and July 2004 and 5 between July 2004 and March 2005. Laparoscopic ventral hernia repair was performed for 49 consecutive patients between July 2004 and March 2005. The patients' characteristics are outlined in Tables 1 and 2. No significant differences in the patients' general and surgical risk factors were identified. The operative time and mesh size were not significantly different (Table 3 ). The length of stay was significantly shorter for patients after laparoscopic ventral hernia repair than for patients after open repair. The follow-up period for the patients was 69 weeks (range, 6-115 weeks) after open hernia repair and 10 weeks (range, 6-25 weeks) after laparoscopic ventral hernia repair.

Surgical complications occurred in 25 cases $(27.2 \%)$ after open ventral hernia repair and in 7 cases $(14.3 \%)$ after laparoscopy $(p=0.09)$. Most of the complications involved infections (Table 4). Surgical-site infections occurred significantly more often in patients after open hernia repair. Among the patients with surgical-site infections, the mesh had to be removed for one patient. For eight patients, the infection was treated using vacuum-assisted closure. Prolonged postoperative pain over 6 weeks was found in $5.4 \%$ of the patients who had open hernia repair and in $6.1 \%$ of those who had laparoscopic ventral repair. Among the open repair patients, two required repetitive nerve infiltrations.

Pain after laparoscopic ventral hernia repair was always localized at the sites of the transfascial sutures. A second laparoscopy was performed for one patient to rule out recurrence. In this patient and another patient, the pain was treated successfully by removing up to four transfascial sutures with the patient under local anesthesia.

Nonsurgical complications were experienced by seven patients $(7.6 \%)$ after open repair and one patient (2\%) after laparoscopic repair $(p=0.26)$. One patient died 73 days after open repair of multiorgan failure attributable to surgical-site infection and pneumonia.

The mean cost of surgery was 2,314 \pm 925 euros for open ventral hernia repair and 2,853 $\pm 1,147$ euros for laparoscopic repair $(p=0.03)$. The hospital cost was $7,312 \pm 7,697$ euros for open repair and 4,902 $\pm 2,514$ euros for laparoscopic repair $(p=0.04)$. The overall costs were $9,787 \pm 8,021$ euros for open repair and $7,654 \pm 3,204$ for laparoscopic repair $(p=0.02)$.

\section{Discussion}

In the current series, laparoscopic ventral hernia repair using a dual-layer polypropylene mesh and transfascial suturing significantly reduced surgical-site infections, length of hospital stay, and costs as compared with open mesh repair.

Surgical-site infections after open mesh repair occurred for $14 \%$ of the patients. This rate is comparable with the $4 \%$ to $18 \%$ rate reported in published large series [5]. In our series, only one mesh had to be removed in each group because of infection.

In contrast to the use of ePTFE meshes, conservative treatment of infected polypropylene-based meshes was possible for four patients after open repair $[5,6]$. The incidence of seroma formation was markedly lower after laparoscopic repair than in series using ePTFE mesh $[3,7]$. This low incidence of seroma formation may be attributable to the fact that the large pores of the duallayer polypropylene mesh allows a more efficient resorption of wound secretion into the abdominal cavity than afforded by ePTFE meshes.

The rates of fistula formation ( 1 for open vs 0 for laparoscopic surgery) and unrecognized bowel injuries ( 1 in each group) did not differ between the two groups. These complications were well within the range up to $3 \%$ for fistula formation and up to $6 \%$ for bowel injury in other published series [1, 2, 7, 9, 13].

Transfascial sutures result in a very rigid fixation of the mesh to the fasciae of the abdominal wall. In vivo experiments showed that the tension of the mesh with transfascial sutures is 2.5 times greater than fixation 
Table 1. Patient characteristics

\begin{tabular}{|c|c|c|c|}
\hline & $\begin{array}{l}\text { Open } \\
(n=92)\end{array}$ & $\begin{array}{l}\text { Laparoscopic } \\
(n=49)\end{array}$ & $p$ Value \\
\hline Male/female & $59 / 33$ & $33 / 19$ & 0.54 \\
\hline Age (years): $n$ (range) & $62(28-84)$ & $57(20-84)$ & 0.43 \\
\hline ASA (SD) & & & 0.46 \\
\hline $1-2$ & 33 & 21 & \\
\hline $3-4$ & 42 & 22 & \\
\hline BMI $\left(\mathrm{kg} / \mathrm{m}^{2}\right): n$ (range) & $27.5(17-52)$ & $29.0(20-65)$ & 0.53 \\
\hline Previous hernia repair: $n(\%)$ & $18(19.5)$ & $9(18.4)$ & 1.00 \\
\hline \multicolumn{4}{|l|}{ Type of previous laparotomy: $n(\%)$} \\
\hline Midline & $57(62)$ & $28(57.1)$ & 0.59 \\
\hline Pfannenstiel & $6(6.5)$ & $0(0.0)$ & 0.09 \\
\hline Transverse epigastric & $10(10.9)$ & $7(14.3)$ & 0.59 \\
\hline Lumbotomy & $3(3.3)$ & $3(6.1)$ & 0.42 \\
\hline Appendectomy & $2(2.2)$ & $1(2)$ & 1.00 \\
\hline No previous abdominal surgery & $14(15.2)$ & $10(20.4)$ & 0.48 \\
\hline
\end{tabular}

ASA, American Society of Anesthesiology; BMI, body mass index

Table 2. Patient risk factors for hernia formation

\begin{tabular}{llll}
\hline Risk factors & $\begin{array}{l}\text { Open } \\
(n=92)\end{array}(\%)$ & $\begin{array}{l}\text { Laparoscopic } \\
(n=49)\end{array}(\%)$ & $p$ Value \\
\hline Obesity & $28(30.4)$ & $11(22.4)$ & 0.33 \\
Cardiovascular disease & $32(34.8)$ & $24(49)$ & 0.11 \\
Immunosuppression & $13(14.1)$ & $6(12.2)$ & 1.00 \\
COPD & $7(7.6)$ & $9(18.4)$ & 0.09 \\
Smoking & $7(7.6)$ & $8(16.3)$ & 0.15 \\
Renal failure & $6(6.5)$ & $4(8.2)$ & 0.74 \\
\hline
\end{tabular}

COPD, chronic obstructive pulmonary disease

Table 3. Surgical details

\begin{tabular}{lcll}
\hline & $\begin{array}{l}\text { Open } \\
(n=92) n(\text { range })\end{array}$ & $\begin{array}{l}\text { Laparoscopic } \\
(n=49)\end{array}$ (range) & $p$ Value \\
\hline $\begin{array}{l}\text { Operative time (min) } \\
\text { Conversions }\end{array}$ & $155(60-375)$ & $158(50-360)$ & 0.28 \\
Mesh size $\left(\mathrm{cm}^{2}\right)$ & $400(40-1,000)$ & $500(144-1,100)$ & 0.36 \\
LOS (days) & $7(2-87)$ & $6(3-32)$ & 0.02 \\
\hline
\end{tabular}

LOS, length of hospital days

with metallic staples [14]. The use of fixation by sutures has only the advantage of being applicable in all kinds of hernias independently of their size, and of avoiding the exposure of metallic materials to the intestines with their potential sequelae (adhesions, small bowel obstruction and perforation, and hernia formation) $[8,10]$.

Pain attributable to nerve entrapment and tight suturing was relieved by suture removal for two patients under local anesthesia.

This study has shown decreased overall hospital costs for laparoscopic hernia repair despite higher operative costs. The types of fixation device and mesh are important factors contributing to direct operative costs. Whether the use of staplers may markedly decrease operative time and consequently costs remains to be proved. In addition, to prove an overall cost reduc-
Table 4. Peri- and postoperative morbidity

\begin{tabular}{|c|c|c|c|}
\hline & $\begin{array}{l}\text { Open } \\
(n=92)\end{array}$ & $\begin{array}{l}\text { Laparoscopic } \\
(n=49)\end{array}$ & $p$ Value \\
\hline \multicolumn{4}{|c|}{ Surgical complications: $n(\%)$} \\
\hline Surgical-site infection & $13(14.1)$ & $1(2)$ & 0.03 \\
\hline Pain & $5(5.4)$ & $3(6.1)$ & 1.00 \\
\hline Seroma & $5(5.4)$ & $2(4.1)$ & 1.00 \\
\hline Cellulitis & $3(3.3)$ & 0 & 0.55 \\
\hline $\begin{array}{l}\text { Unrecognized small } \\
\text { bowel perforation }\end{array}$ & $1(1.1)$ & $1(2)$ & 0.99 \\
\hline Postoperative ileus & $3(3.3)$ & $1(2)$ & 1.00 \\
\hline Hematoma & $1(1.1)$ & 0 & 1.00 \\
\hline Fistula & $1(1.1)$ & 0 & 1.00 \\
\hline \multicolumn{4}{|c|}{ Nonsurgical complications: $n(\%)$} \\
\hline Pneumonia & $3(3.3)$ & 0 & 0.55 \\
\hline Atrial fibrillation & $2(2.2)$ & 0 & 0.54 \\
\hline Renal failure & $1(1.1)$ & 0 & 1.00 \\
\hline Diarrhea/Colitis & $1(1.1)$ & $1(2)$ & 0.99 \\
\hline
\end{tabular}

tion, indirect and intangible costs will need to be assessed prospectively.

Although laparoscopic ventral hernia repair had advantages over open surgery in the short-term outcome, the rate of recurrence in the long term will ultimately define its impact. To answer this question with unbiased scientific evidence, large, controlled randomized trials are required. Before initiation of these studies, the risks and advantages of various mesh materials and their fixation methods must be characterized.

\section{References}

1. Balen EM, Diez-Caballero A, Hernandez-Lizoain JL, Pardo F, Torramade JR, Regueira FM, Cienfuegos JA (1998) Repair of ventral hernias with expanded polytetrafluoroethylene patch. Br J Surg 85: 1415-1418

2. Bauer JJ, Harris MT, Kreel I, Gelernt IM (1999) Twelve-year experience with expanded polytetrafluoroethylene in the repair of abdominal wall defects. Mt Sinai J Med 66: 20-25 
3. Carbajo MA, Martp del Olmo JC, Blanco JI, Toledano M, de la Cuesta C, Ferreras C, Vaquero C (2003) Laparoscopic approach to incisional hernia. Surg Endose 17: 118-122

4. Carbonell AM, Matthews BD, Dreau D, Foster M, Austin CE, Kercher KW, Sing RF, Heniford BT (2005) The susceptibility of prosthetic biomaterials to infection. Surg Endosc 19: 430-435

5. Cassar K, Munro A (2002) Surgical treatment of incisional hernia. Br J Surg 89: 534-545

6. Diaz JJ Jr, Gray BW, Dobson JM, Grogan EL, May AK, Miller R, Guy J, O'Neill P, Morris JA Jr (2004) Repair of giant abdominal hernias: does the type of prosthesis matter? Am Surg 70: 396-401, discussion 401-402

7. Heniford BT, Park A, Ramshaw BJ, Voeller G (2003) Laparoscopic repair of ventral hernias: nine years' experience with 850 consecutive hernias. Ann Surg 238: 391-399, discussion 399400

8. Karahasanoglu T, Onur E, Baca B, Hamzaoglu I, Pekmezci S, Boler DE, Kilic N, Altug T (2004) Spiral tacks may contribute to intraabdominal adhesion formation. Surg Today 34: 860-864

9. Koehler RH, Begos D, Berger D, Carey S, LeBlanc K, Park A, Ramshaw B, Smoot R, Voeller G (2003) Minimal adhesions to
ePTFE mesh after laparoscopic ventral incisional hernia repair: reoperative findings in 65 cases. J Soc Lap Endosc Surg 7: 335-340

10. Ladurner R, Mussack T (2004) Small bowel perforation due to protruding spiral tackers: a rare complication in laparoscopic incisional hernia repair. Surg Endosc 18: 1001

11. Luijendijk RW, Hop WC, van den Tol MP, de Lange DC, Braaksma MM, JN IJ, Boelhouwer RU, de Vries BC, Salu MK, Wereldsma JC, Bruijninckx CM, Jeekel J (2000) A comparison of suture repair with mesh repair for incisional hernia. N Engl J Med 343: 392-398

12. McGinty JJ, Hogle NJ, McCarthy H, Fowler DL (2005) A comparative study of adhesion formation and abdominal wall ingrowth after laparoscopic ventral hernia repair in a porcine model using multiple types of mesh. Surg Endosc 19: 786-790

13. McLanahan D, King LT, Weems C, Novotney M, Gibson K (1997) Retrorectus prosthetic mesh repair of midline abdominal hernia. Am J Surg 173: 445-449

14. van't Riet $M$, de van Vos Steenwijk PJ, Kleinrensink GJ, Steyerberg EW, Bonjer HJ (2002) Tensile strength of mesh fixation methods in laparoscopic incisional hernia repair. Surg Endosc 16: $1713-1716$ 